\section{(2) OPEN ACCESS}

\begin{abstract}
- Additional material is published online only. To view please visit the journal online (http://dx.doi.org/10.1136 thoraxjnl-2020-215107)
\end{abstract}

${ }^{1}$ Department of Internal Medicine, Seoul National University College of Medicine, Seoul, South Korea

${ }^{2}$ Division of Pulmonary and Critical Care Medicine, Department of Internal Medicine, Seoul National University Bundang Hospital, Seongnam, South Korea ${ }^{3}$ Department of Radiology, Seoul National University Bundang Hospital, Seongnam, South Korea

${ }^{4}$ Department of Pathology and Translational Medicine, Seoul National University Bundang Hospital, Seongnam, South Korea

${ }^{5}$ Medical Research Collaborating Center, Seoul National University Bundang Hospital, Seongnam, South Korea

\section{Correspondence to} Professor Choon-Taek Lee, Internal Medicine, Seoul National University Bundang Hospital, Seongnam 13620, South Korea; ctlee@snu.ac.kr

Received 22 April 2020 Revised 25 January 2021 Accepted 26 January 2021 Published Online First 15 April 2021

Check for updates

(C) Author(s) (or their employer(s)) 2021. Re-use permitted under CC BY-NC. No commercial re-use. See rights and permissions. Published by BMJ.

To cite: Kim YW, Kwon BS, Lim SY, et al. Thorax

2021;76:980-988.

\title{
Lung cancer probability and clinical outcomes of baseline and new subsolid nodules detected on low- dose CT screening
}

\author{
Yeon Wook Kim $\odot$, 1,2 Byoung Soo Kwon, 1,2 Sung Yoon Lim, 1,2 Yeon Joo Lee, 1,2 \\ Jong Sun Park, ${ }^{1,2}$ Young-Jae Cho, ${ }^{1,2}$ Ho $\|$ Yoon, ${ }^{1,2}$ Kyung Won Lee, Jae Ho Lee, ${ }^{1,2}$ \\ Jin-Haeng Chung, ${ }^{4}$ Eunjeong ji, ${ }^{5}$ Choon-Taek Lee (1) 1,2
}

\begin{abstract}
Background Limited data are available regarding the management of subsolid nodules detected on lung cancer screening with low-dose CT (LDCT). We aimed to determine the characteristics of screen-detected subsolid nodules, and to evaluate the probability of lung cancer and the clinical course of subsolid nodules detected at baseline and during follow-up screening. Methods We evaluated 50132 asymptomatic adults (22 631 never-smokers and 27501 ever-smokers) who underwent LDCT screening for lung cancer between May 2003 and June 2019 at a tertiary centre in South Korea. The incidence, characteristics and clinical outcomes of the baseline and new screen-detected subsolid nodules were determined.
\end{abstract}

Results A total of 6725 subsolid nodules (5116 pure ground glass opacity nodules and 1609 partsolid nodules) were detected in 4545 participants (1484 new subsolid nodules detected in 937 (1.9\%) participants; the overall incidence of subsolid nodules: $10.7 \%$ in never-smokers and $7.7 \%$ in eversmokers, $\mathrm{p}<0.001)$. Among 4918 subsolid nodules that underwent follow-up with CT scans (the mean number of CT scans, including the baseline LDCT scan: 4.6), 2116 nodules (30.0\% of baseline subsolid nodules and $78.9 \%$ of new subsolid nodules) resolved spontaneously. Among 293 biopsied subsolid nodules, $227(77.5 \%)$ nodules were diagnosed as lung cancer, of which 226 (99.6\%) were adenocarcinomas. No significant difference was observed in pathological invasiveness or the initial stage between the baseline and new cancerous subsolid nodules. Multivariable analyses revealed that new detection at follow-up screening was significantly associated with a lower probability of lung cancer (OR $0.26,95 \% \mathrm{Cl} 0.14$ to 0.49 ) and overall growth (OR $0.39,95 \% \mathrm{Cl} 0.26$ to 0.59 ), but with a higher probability of resolution (OR $6.30,95 \%$ Cl 5.09 to 7.81$)$.

Conclusions LDCT screening led to a considerably high rate of subsolid nodule detection, particularly in never-smokers. Compared with the baseline subsolid nodules, the new subsolid nodules were associated with a lower probability of lung cancer and higher probability of spontaneous resolution, indicating their more inflammatory nature. Less aggressive follow-up may be allowed for new subsolid nodules, particularly in screening programmes for Asian populations.

\section{Key messages}

What is the key question?

- What are the characteristics, probability of lung cancer and clinical outcomes of baseline and new subsolid nodules detected by low-dose CT screening in the Asian population?

What is the bottom line?

- In a lung cancer screening cohort of 50132 asymptomatic Asian participants, new subsolid nodules had a lower probability of lung cancer and a higher probability of spontaneous resolution than subsolid nodules detected at baseline.

Why read on?

- The results offer insight into the cancer probability and outcomes of screen-detected subsolid nodules and indicate that less aggressive follow-up may be allowed for new subsolid nodules, particularly in screening programmes for Asian populations.

\section{INTRODUCTION}

Following the promising results of mortality reduction from the National Lung Screening Trial (NLST) and the Dutch-Belgian Randomised Lung Cancer Screening (NELSON) trial, ${ }^{1}{ }^{2}$ low-dose CT (LDCT) has been widely introduced for lung cancer screening. Although the US Preventive Services Task Force currently recommends LDCT screening for lung cancer in heavy smokers aged $55-80$ years, ${ }^{3}$ several large cohort studies suggested that LDCT screening might be beneficial to many individuals who do not meet these criteria. ${ }^{45}$ Many other countries do not yet have criteria for LDCT screening. In East Asia, where the incidence of lung cancer among never-smokers is relatively high and increasing ${ }^{67}$ LDCT screening is widely applied to both never- and ever-smokers and to individuals of younger age. $^{89}$

The increased use of LDCT for lung cancer screening has led to a considerable increase in the detection of pulmonary nodules. This has led to increased awareness of screen-detected subsolid nodules, including pure ground glass opacity nodules (GGNs) and part-solid nodules, which are 
detected in a notable proportion of the screened individuals. ${ }^{10} 11$ Although some are transient, persistent subsolid nodules are likely indicative of lung adenocarcinoma and tend to have a different nature from solid cancers, indicating a distinct disease entity. ${ }^{12} 13$ The management of subsolid nodules is important, considering the relatively high likelihood of malignancy, but is complicated and challenging due to their indolent behaviour and heterogeneity in the natural course. ${ }^{14} 15$ To date, due to limited data on the management of subsolid nodules, recommendations vary among guidelines. ${ }^{16-18}$ Particularly, subsolid nodules are more prevalent in women and never-smokers of Asian origin. ${ }^{19}$ Although increasing data on long-term follow-up are available, few studies have investigated the management of screen-detected subsolid nodules. Most of the data of large screening trials come from Caucasians with a significant history of smoking, and these studies report a considerably lower incidence of subsolid nodules than studies conducted in Asia. ${ }^{102021}$

Considering that determining how best to follow-up and manage detected nodules is essential in the era of lung cancer screening, differentiation of nodules found at baseline screening and new nodules found at follow-up screening is particularly important because they differ in developmental time frames. This is supported by the recent data from the NELSON trial, which revealed that the risk of lung cancer is higher with solid nodules that are newly detected at incident screening than with solid nodules detected at baseline screening. ${ }^{22}$ Lung cancers found in incidence screenings tend to exhibit more aggressive features compared with those detected at baseline. ${ }^{23}$ Therefore, for new solid nodules, caution and smaller size cutoffs for evaluation are recommended. ${ }^{18}{ }^{24}$ However, to date, studies on the difference between the baseline and new subsolid nodules are limited. Large trials only included a small number of subsolid nodules due to the low incidence among the study population. ${ }^{25}$ This study, therefore, aimed to assess the incidence and characteristics of screen-detected subsolid nodules in a large cohort including never-smokers in South Korea, and to evaluate the probability of lung cancer and the clinical course of baseline and new screen-detected subsolid nodules.

\section{MATERIALS AND METHODS}

\section{Study design and participants}

This study was designed as a single-centre, retrospective cohort study of participants aged $\geq 18$ years who voluntarily underwent LDCT screening for lung cancer between May 2003 and June 2019 at the Health Promotion Centre of Seoul National University Bundang Hospital, a tertiary centre in South Korea. All participants underwent LDCT screening as part of their health checkups and were asymptomatic at the time of baseline screening. Questionnaires were used to evaluate the smoking status (never-smoker, ex-smoker or current-smoker) and the amount of smoking in pack-years. Neversmokers were defined as participants who had never smoked or had smoked $<100$ cigarettes in their lifetime. ${ }^{26}$ Participants with unknown smoking history at the time of the first LDCT screening were excluded; participants with data on smoking status but without the amount of smoking were included.

Participants with positive nodules, defined as any noncalcified nodule in which the longest diameter was at least $4 \mathrm{~mm}$, were referred to the pulmonary division. Decisions regarding follow-up and pathological evaluations were made by the attending specialist in the pulmonary division. Based on guidelines at the time, the decision to perform an invasive biopsy mainly depended on the radiological aspects of the nodule and was not additionally weighted by other demographic factors. The pathological diagnosis of a nodule was performed using video-assisted thoracoscopic surgery, percutaneous needle biopsy, or bronchoscopic biopsy. For this study, of the screened participants, those with pulmonary subsolid nodules were retrospectively evaluated. All participants were categorised into two groups; never-smokers and ever-smokers, based on their smoking history. As the smoking amount information was missing for a proportion of the ever-smokers, we were unable to further stratify this group by the amount of smoking. The requirement for obtaining informed consent was waived.

\section{Procedures and outcomes}

Unenhanced LDCT scans were performed at a peak tube voltage of $100 \mathrm{kV}$ and a reference tube current of 20-50 mA using one of the following multidetector row scanners: Mx-8000 IDT 1, Mx-8000 IDT 2, Mx-8000 IDT 16 (all by Philips Medical Systems, Cleveland, Ohio, USA); Brilliance-64, Brilliance iCT 256 (Philips Medical Systems, Best, the Netherlands). All LDCT images were reconstructed with $3 \mathrm{~mm}$ or thinner slices in the axial plane and a $3 \mathrm{~mm}$ slice in the coronal plane and were initially stored in a dedicated electronic Picture Archiving and Communication System. All images were initially interpreted by board-certified experienced chest radiologists. For this study, a pulmonary physician (YWK) and a radiologist (KWL) reviewed all images with reports of positive subsolid nodules, which were defined as pure GGNs or as part-solid nodules in which the longest diameter was at least $4 \mathrm{~mm}$. Screening images taken before and after the first report of a subsolid nodule were also reviewed to determine the time frame of occurrence and to confirm a diagnosis of a subsolid nodule. The size of a subsolid nodule was defined by its maximal diameter on the lung window setting. The determination of pure GGN and part-solid nodule was based on the tumour shadow disappearance rate (TDR), as follows: $T D R=0$ for pure GGNs and $0<$ TDR $<1$ for part-solid nodules. ${ }^{15}$ For part-solid nodules, the size of the solid component was measured with its maximal diameter on the mediastinal window setting. All reviewed subsolid nodules were classified by using the lung-reporting and data system (RADS) criteria (edition 1.0). ${ }^{24}$ For inconsistent findings, a consensus was reached by a discussion on the confirmation, location and characteristics, including the lung-RADS criteria, for the reviewed subsolid nodules.

For detected subsolid nodules, the location, Lung-RADS category at first detection, and the duration and total number of CT scans during follow-up were assessed. All follow-up CT scans were assessed to evaluate the clinical course and outcomes of the subsolid nodules. Results from CT scans taken for later screening after the detection of subsolid nodules were included as additional follow-ups. The outcome of the detected subsolid nodules was determined, based on the final status on the last CT scan. Growth of a subsolid nodule was defined as (1) $\geq 2 \mathrm{~mm}$ increase in size, (2) $\geq 2 \mathrm{~mm}$ increase in the solid component of a partsolid nodule or (3) emerging new solid component of any size in a pure GGN. ${ }^{27}$ Resolution of a subsolid nodule was defined as (1) disappearance or (2) a decrease in the total size or solid component of $\geq 2 \mathrm{~mm}$ from initial detection. Other conditions were defined as stable. For each subsolid nodule that underwent invasive procedures for a pathological diagnosis, the type of diagnostic procedures, and any associated complications were evaluated. The pathological reports, final diagnosis of biopsied subsolid nodules, and staging reports and records of initial treatment and outcomes for diagnosed lung cancer were obtained.

For participants who had synchronous multiple lung nodules, medical records revealed the specific target nodule that underwent biopsy and specific pathological results for every biopsied nodule. Participants who had screen-detected subsolid nodules but who had received a pathological diagnosis after 
the development of cancer-related symptoms were included for outcome analyses. The pathological classification and staging of lung cancer described in this study were based on the 2015 WHO Classification and the International Association for the Study of Lung Cancer and the American Joint Committee on Cancer Stage Classification of non-small-cell lung cancer, eighth edition. ${ }^{28-30}$

\section{Statistical analysis}

Continuous data are presented as means and SD, whereas categorical data are presented as numbers and proportions (\%). To compare clinical and radiological characteristics between groups, Student's t-test was used to analyse continuous variables and Pearson's $\chi^{2}$ test or Fisher's exact test were used to analyse categorical variables. Estimation and comparison of the cumulative incidence of invasive biopsy and lung cancer diagnosis during the follow-up period were conducted by using the Cox proportional hazards regression model for clustered data with adjustments for potential factors and excluding variables that showed multicollinearity. Univariable and multivariable analyses for potential factors affecting the outcomes (diagnosis of lung cancer, growth and resolution) of screen-detected subsolid nodules were performed with the generalised estimating equations method regarding cases of multiple nodules from one participant. The models were adjusted for sex, age, smoking status and variables with $\mathrm{p}$ values less than 0.2 in univariable analyses with exclusion of variables that showed multicollinearity. No covariates included in the regression models had missing values. The $95 \%$ CIs were calculated; $p$ values $<0.05$ were considered statistically significant. All analyses were performed using SAS, V.9.4 (SAS Institute) and STATA, V.16.0 (StataCorp).

\section{RESULTS}

\section{Participant characteristics}

Figure 1 presents a flow chart of the study. During the study period, 54189 participants underwent LDCT for lung cancer screening. After excluding 4057 participants with unknown smoking history, 50132 participants (22631 never-smokers and 27501 ever-smokers) were analysed. The baseline characteristics of all participants are described in online supplemental table 1. Subsolid nodules were detected in $2426(10.7 \%)$ never-smokers and 2119 (7.7\%) ever-smokers $(\mathrm{p}<0.001)$, with the majority of subsolid nodules detected at baseline screening. Of the screened participants, $225(0.4 \%)$ required invasive biopsy for diagnosis of the detected subsolid nodules, and 193 (0.4\%) were diagnosed with lung cancer.

Table 1 provides the baseline characteristics of participants with screen-detected subsolid nodules. Regardless of smoking status, over one-third of participants with screen-detected subsolid nodules were aged $<50$ years at baseline. Compared with ever-smokers, never-smokers with screen-detected subsolid nodules tended to be female $(7.2 \%$ vs $67.7 \%, \mathrm{p}<0.001)$, have subsolid nodules detected at the first screening (74.0\% vs $84.1 \%$, $\mathrm{p}<0.001)$ and have a single subsolid nodule $(71.7 \%$ vs $76.7 \%$, $\mathrm{p}<0.001)$. The proportion of participants with screen-detected subsolid nodules requiring invasive biopsy for a pathological diagnosis, and those finally diagnosed with lung cancer, did not significantly differ between never-smokers and ever-smokers.

\section{Characteristics and clinical outcomes associated with screen- detected subsolid nodules}

Online supplemental table 2 presents the characteristics and outcomes of 6725 (5,241 baseline and 1484 new) screen-detected subsolid nodules. Compared with baseline subsolid nodules, new subsolid nodules tended to present in male $(57.2 \%$ vs $76.3 \%, \mathrm{p}<0.001)$ and in ever-smokers $(44.5 \%$ vs $61.3 \%, \mathrm{p}<0.001)$, be part-solid $(22.0 \%$ vs $30.7 \%, \mathrm{p}<0.001)$ and require additional follow-up $(68.8 \%$ vs $88.3 \%, \mathrm{p}<0.001)$. When evaluating subsolid nodules that underwent additional follow-up after first detection, baseline subsolid nodules had a lower rate of resolution $(30.0 \%$ vs $78.9 \% \mathrm{p}<0.001)$ and a higher growth rate $(7.1 \%$ vs $2.5 \%, \mathrm{p}<0.001)$ than new subsolid nodules. A higher rate of undergoing invasive biopsy (5.1\% vs $1.8 \%$, $\mathrm{p}<0.001)$ and lung cancer diagnosis $(4.0 \%$ vs $1.1 \%, \mathrm{p}<0.001)$ was observed for baseline subsolid nodules compared with new subsolid nodules. Subgroup analyses on the characteristics and clinical course

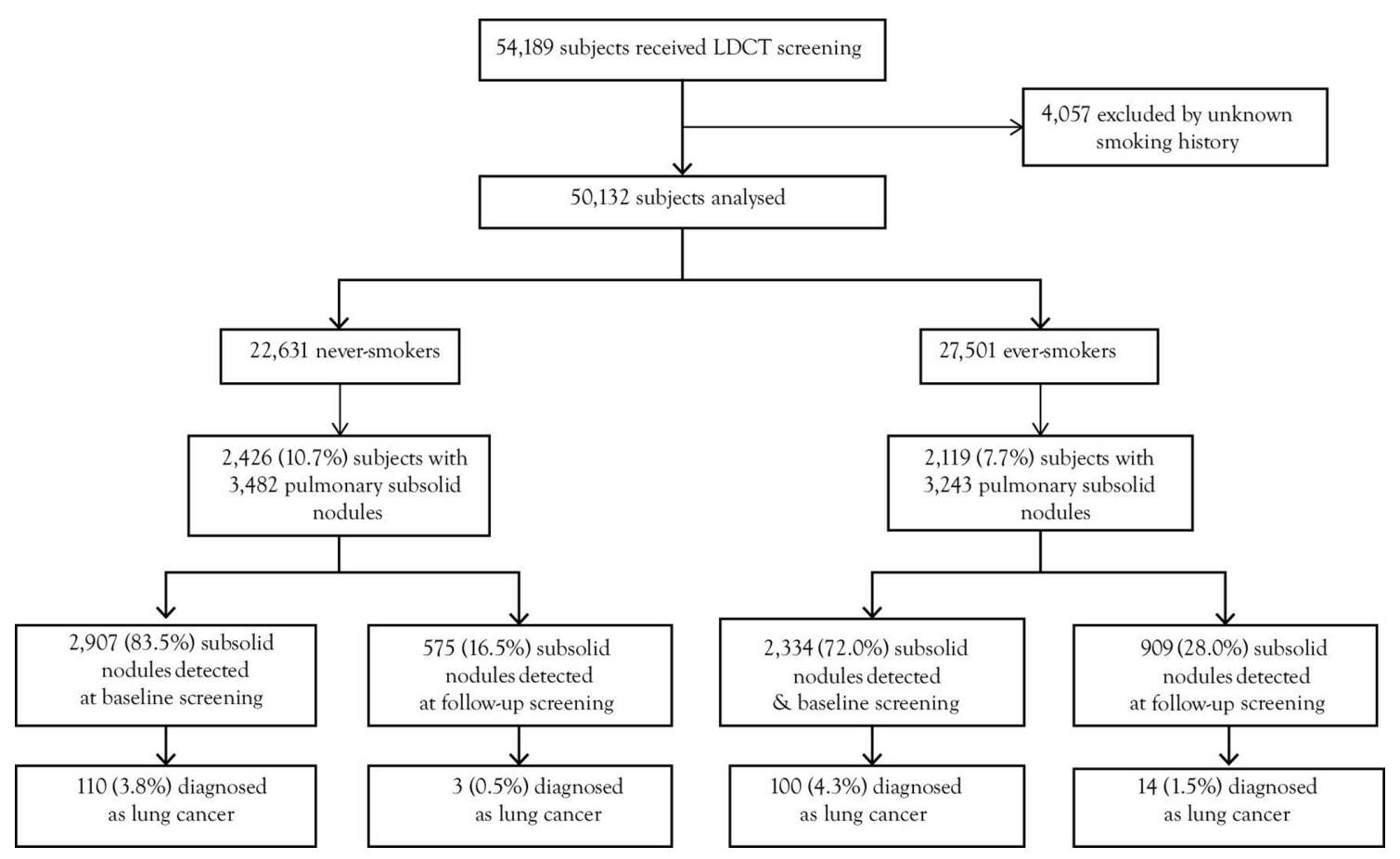

Figure 1 Flow diagram of the study population. 
Table 1 Characteristics of participants with positive subsolid nodules detected on low-dose chest CT screening

\begin{tabular}{|c|c|c|c|c|}
\hline & Total $(n=4545)$ & $\begin{array}{l}\text { Never-smoker } \\
(n=2426)\end{array}$ & $\begin{array}{l}\text { Ever-smoker } \\
(\mathrm{n}=2119)\end{array}$ & $P$ value* \\
\hline Age at first screening & & & & $<0.001$ \\
\hline$<45$ years & $1154(25.4)$ & $506(20.9)$ & $648(30.6)$ & \\
\hline $45-49$ years & $751(16.5)$ & $379(15.6)$ & $372(17.6)$ & \\
\hline $50-54$ years & 796 (17.5) & $413(17.0)$ & $383(18.1)$ & \\
\hline $55-59$ years & $684(15.0)$ & 403 (16.6) & $281(13.3)$ & \\
\hline $60-64$ years & $493(10.8)$ & $291(12.0)$ & $202(9.5)$ & \\
\hline $65-69$ years & $346(7.6)$ & $208(8.6)$ & $138(6.5)$ & \\
\hline $70-74$ years & $206(4.5)$ & $141(5.8)$ & $65(3.1)$ & \\
\hline$\geq 75$ years & $115(2.5)$ & $85(3.5)$ & $30(1.4)$ & \\
\hline Mean \pm SD & $52.2 \pm 11.1$ & $53.8 \pm 11.2$ & $50.4 \pm 10.7$ & \\
\hline Sex, male, n (\%) & $2749(60.5)$ & $783(32.3)$ & $1966(92.8)$ & $<0.001$ \\
\hline $\begin{array}{l}\text { Subsolid nodule(s) detected at } \\
\text { first screening, } \mathrm{n}(\%)\end{array}$ & 3608 (79.4) & $2040(84.1)$ & $1568(74.0)$ & $<0.001$ \\
\hline $\begin{array}{l}\text { No subsolid nodule at first } \\
\text { screening but new subsolid } \\
\text { nodule(s) detected during } \\
\text { follow-up screening, } n(\%)\end{array}$ & $937(20.6)$ & 386 (15.9) & $551(26.0)$ & $<0.001$ \\
\hline $\begin{array}{l}\text { Participants with single subsolid } \\
\text { nodule, } \mathrm{n}(\%)\end{array}$ & 3380 (74.4) & $1860(76.7)$ & $1520(71.7)$ & $<0.001$ \\
\hline $\begin{array}{l}\text { Participants with multiple } \\
\text { subsolid nodules, } \mathrm{n}(\%)\end{array}$ & $1165(25.6)$ & $566(23.3)$ & $599(28.3)$ & $<0.001$ \\
\hline $\begin{array}{l}\text { Underwent invasive biopsy of } \\
\text { subsolid nodule, } n(\%) \dagger\end{array}$ & $225(5.0)$ & $114(4.7)$ & $111(5.2)$ & 0.403 \\
\hline $\begin{array}{l}\text { Diagnosed as lung cancer, } \\
\mathrm{n}(\%)\end{array}$ & $193(4.2)$ & $98(4.0)$ & $95(4.5)$ & 0.459 \\
\hline $\begin{array}{l}\text { Diagnosed as other } \\
\text { malignancy, } \mathrm{n}(\%) \ddagger\end{array}$ & $1(0)$ & $0(0)$ & $1(0)$ & 0.466 \\
\hline $\begin{array}{l}\text { Diagnosed as benign (false- } \\
\text { positive), } n(\%)\end{array}$ & $31(0.7)$ & $16(0.7)$ & $15(0.7)$ & 0.843 \\
\hline
\end{tabular}

of the screen-detected pure GGNs and part-solid nodules are provided in tables 2 and 3 , respectively. In general, differences in the baseline characteristics and clinical outcomes between baseline and new nodules were similar for pure GGNs and part-solid nodules.

Figure 2 presents the cumulative hazards of invasive biopsy (figure 2A) and lung cancer diagnosis (figure 2B) after the first detection in baseline and new subsolid nodules. The median (IQR) follow-up time was 35.1 (6.8-71.3) months for baseline subsolid nodules and 35.1 (13.7-58.5) months for new subsolid nodules. Multivariate Cox regression model estimates revealed that, after adjusting for potential covariates, new subsolid nodules had a lower risk of undergoing a biopsy (HR 0.39, 95\% CI 0.26 to 0.58 ) and lung cancer diagnosis (HR $0.31,95 \% \mathrm{CI} 0.19$ to $0.51)$ than baseline subsolid nodules. The detailed results of the Cox proportional hazard models are provided in online supplemental table 3.

The diagnostic procedures and related complications and final pathological diagnosis of screen-detected subsolid nodules are provided in table 4. Among 293 subsolid nodules requiring invasive biopsy, 227 (77.5\%, 210 detected at baseline and 17 newly detected) were diagnosed as lung cancer. Compared with baseline subsolid nodules, new subsolid nodules tended to be diagnosed as benign $(20.7 \%$ vs $37.0 \%, \mathrm{p}=0.051)$ after invasive biopsy. The rates of atypical adenomatous hyperplasia (AAH, $58.2 \%$ vs $20.0 \%$ ) or focal fibrosis (16.4\% vs $0 \%$ ) were higher for baseline subsolid nodules that were found to be false-positive after biopsy than those for the new subsolid nodules. The characteristics of lung cancer diagnosed from
Table 2 Characteristics and clinical course of pure GGNs detected at baseline screening and follow-up screening

\begin{tabular}{|c|c|c|c|c|}
\hline & Total $(n=5116)$ & $\begin{array}{l}\text { Baseline pure } \\
\text { GGN }(n=4088)\end{array}$ & $\begin{array}{l}\text { New pure } \\
\text { GGN }(n=1028)\end{array}$ & P value* \\
\hline $\begin{array}{l}\text { Nodule diameter at first } \\
\text { detection }(\mathrm{mm}) \text {, mean } \pm S D\end{array}$ & $6.1 \pm 2.1$ & $6.1 \pm 2.2$ & $6.2 \pm 1.9$ & 0.113 \\
\hline $\begin{array}{l}\text { Sex of participants with } \\
\text { nodules (male), } \mathrm{n}(\%)\end{array}$ & 3039 (59.4) & $2278(55.7)$ & $761(74.0)$ & $<0.001$ \\
\hline $\begin{array}{l}\text { Smoking status of } \\
\text { participants with nodules, } \\
\mathrm{n}(\%)\end{array}$ & & & & $<0.001$ \\
\hline Never-smoker & $2731(53.4)$ & $2319(56.7)$ & $412(40.1)$ & \\
\hline Ever-smoker & $2385(46.6)$ & $1769(43.3)$ & $616(59.9)$ & \\
\hline Location, n (\%) & & & & $<0.001$ \\
\hline Right upper lobe & $1404(27.4)$ & $1137(27.8)$ & $267(26.0)$ & \\
\hline Right middle lobe & $494(9.7)$ & 387 (9.5) & $107(10.4)$ & \\
\hline Right lower lobe & $1158(22.6)$ & $887(21.7)$ & $271(26.4)$ & \\
\hline Left upper lobe & $1084(21.2)$ & $908(22.2)$ & $176(17.1)$ & \\
\hline Left lower lobe & $976(19.1)$ & 769 (18.8) & $207(20.1)$ & \\
\hline $\begin{array}{l}\text { Lung-RADS category at first } \\
\text { detection of nodule, } n(\%)\end{array}$ & & & & 0.457 \\
\hline 2 & $5082(99.3)$ & 4058 (99.3) & 1024 (99.6) & \\
\hline 3 & $33(0.6)$ & $29(0.7)$ & $4(0.4)$ & \\
\hline $4 \mathrm{~A}$ & 0 & 0 & 0 & \\
\hline 4B & 0 & 0 & 0 & \\
\hline $4 X$ & $1(0.0)$ & $1(0.0)$ & $0(0)$ & \\
\hline $\begin{array}{l}\text { Pure GGNs that received } \\
\text { additional follow-up } \\
\text { (including a later } \\
\text { screening), } \mathrm{n}(\%)\end{array}$ & $3503(68.5)$ & 2614 (63.9) & $889(86.5)$ & $<0.001$ \\
\hline $\begin{array}{l}\text { No of } C T \text { scans, including } \\
\text { the first } L D C T \text {, mean } \pm S D\end{array}$ & $4.7 \pm 3.2$ & $4.2 \pm 3.1$ & $5.9 \pm 3.0$ & $<0.001$ \\
\hline $\begin{array}{l}\text { Duration from first } \\
\text { detection of nodule to } \\
\text { the last CT scan (months), } \\
\text { mean } \pm \text { SD }\end{array}$ & $46.6 \pm 39.7$ & $50.5 \pm 41.7$ & $35.4 \pm 30.8$ & $<0.001$ \\
\hline \multicolumn{5}{|l|}{$\begin{array}{l}\text { Outcome of pure GGNs } \\
\text { after follow-up, n/N (\%) }\end{array}$} \\
\hline Resolutiont & $\begin{array}{l}1,317 / 3,503 \\
(37.6)\end{array}$ & $655 / 2,614(25.1)$ & $662 / 889(74.5)$ & $<0.001$ \\
\hline Completely disappeared & $\begin{array}{l}1,271 / 3,503 \\
(36.3)\end{array}$ & $632 / 2,614(24.2)$ & $639 / 889$ (71.9) & $<0.001$ \\
\hline $\begin{array}{l}\text { Decreased in size or solid } \\
\text { portion }\end{array}$ & $46 / 3,503(1.3)$ & $23 / 2,614(0.9)$ & 23/889 (2.6) & $<0.001$ \\
\hline Stable & $\begin{array}{l}2,026 / 3,503 \\
(57.8)\end{array}$ & $1,819 / 2,614(69.6)$ & 207/889 (23.3) & $<0.001$ \\
\hline Growth $\ddagger$ & $160 / 3,503(4.6)$ & $140 / 2,614(5.4)$ & $20 / 889(2.2)$ & $<0.001$ \\
\hline $\begin{array}{l}\text { Pure GGNs that underwent } \\
\text { invasive biopsy, } \mathrm{n}(\%)\end{array}$ & $117(2.3)$ & $104(2.5)$ & $13(1.3)$ & 0.014 \\
\hline $\begin{array}{l}\text { Diagnosed as lung cancer, } \\
\text { n (\%) }\end{array}$ & $76(1.5)$ & $67(1.6)$ & $9(0.9)$ & 0.070 \\
\hline $\begin{array}{l}\text { Diagnosed as benign (false- } \\
\text { positive), } \mathrm{n}(\%)\end{array}$ & $41(0.8)$ & $37(0.9)$ & $4(0.4)$ & 0.097 \\
\hline
\end{tabular}

screen-detected subsolid nodules are provided in table 5. All but one subsolid nodules were preinvasive or invasive adenocarcinomas. The pathological classification and initial staging did not significantly differ between baseline and new subsolid nodules. Online supplemental table 4 shows the classification of diagnosed adenocarcinomas, based on the International Classification of Diseases for Oncology code, and the 2015 WHO classification of lung tumours. ${ }^{31}$ 


\begin{tabular}{|c|c|c|c|c|}
\hline & Total $(n=1609)$ & $\begin{array}{l}\text { Baseline part- } \\
\text { solid nodule } \\
(\mathrm{n}=1153)\end{array}$ & $\begin{array}{l}\text { New part-solid } \\
\text { nodule }(\mathrm{n}=456)\end{array}$ & P value* \\
\hline $\begin{array}{l}\text { Nodule diameter at first } \\
\text { detection }(\mathrm{mm}) \text {, mean } \pm S D\end{array}$ & $9.3 \pm 5.2$ & $9.7 \pm 5.5$ & $8.4 \pm 4.4$ & $<0.001$ \\
\hline $\begin{array}{l}\text { Sex of participants with } \\
\text { nodules (male), } \mathrm{n}(\%)\end{array}$ & $1093(67.9)$ & $722(62.6)$ & $371(81.4)$ & $<0.001$ \\
\hline $\begin{array}{l}\text { Smoking status of } \\
\text { participants with nodules, } \\
\text { n (\%) }\end{array}$ & & & & $<0.001$ \\
\hline Never-smoker & $751(46.7)$ & $588(51.0)$ & $163(35.7)$ & \\
\hline Ever-smoker & $858(53.3)$ & $565(49.0)$ & $293(64.3)$ & \\
\hline Location, n (\%) & & & & 0.169 \\
\hline Right upper lobe & $421(26.2)$ & $312(27.1)$ & $109(23.9)$ & \\
\hline Right middle lobe & $152(9.4)$ & $104(9.0)$ & $48(10.5)$ & \\
\hline Right lower lobe & $384(23.9)$ & $268(23.2)$ & $116(25.4)$ & \\
\hline Left upper lobe & $360(22.4)$ & $270(23.4)$ & $90(19.7)$ & \\
\hline Left lower lobe & $292(18.1)$ & $199(17.3)$ & $93(20.4)$ & \\
\hline $\begin{array}{l}\text { Lung-RADS category at first } \\
\text { detection of nodule, } \mathrm{n}(\%)\end{array}$ & & & & $<0.001$ \\
\hline 2 & $125(7.8)$ & $125(10.8)$ & $0(0)$ & \\
\hline 3 & $890(55.3)$ & $786(68.2)$ & $104(22.8)$ & \\
\hline $4 \mathrm{~A}$ & $405(25.2)$ & $164(14.2)$ & $241(52.9)$ & \\
\hline $4 B$ & $182(11.3)$ & $71(6.2)$ & $111(24.3)$ & \\
\hline $4 \mathrm{X}$ & $7(0.4)$ & $7(0.6)$ & $0(0)$ & \\
\hline $\begin{array}{l}\text { Part-solid nodules that } \\
\text { underwent additional } \\
\text { follow-up (including later } \\
\text { screening), } n(\%)\end{array}$ & $1415(87.9)$ & $993(86.1)$ & $422(92.5)$ & $<0.001$ \\
\hline $\begin{array}{l}\text { No of CT scans, including } \\
\text { the first LDCT scan, } \\
\text { mean } \pm \text { SD }\end{array}$ & $4.4 \pm 2.7$ & $3.7 \pm 2.3$ & $6.1 \pm 3.0$ & $<0.001$ \\
\hline $\begin{array}{l}\text { Duration from first } \\
\text { detection of a nodule } \\
\text { to the last CT scan } \\
\text { (months), mean } \pm S D\end{array}$ & $35.4 \pm 37.8$ & $35.3 \pm 38.6$ & $35.8 \pm 35.7$ & 0.797 \\
\hline $\begin{array}{l}\text { Outcome of part-solid } \\
\text { nodules after follow-up, } \\
\mathrm{n} / \mathrm{N}(\%)\end{array}$ & & & & \\
\hline Resolutiont & 799/1415 (56.5) & $427 / 993(43.0)$ & 372/422 (88.2) & $<0.001$ \\
\hline Completely disappeared & $758 / 1415$ (53.6) & 405/993 (40.8) & 353/422 (83.6) & $<0.001$ \\
\hline $\begin{array}{l}\text { Decreased in size or } \\
\text { solid portion }\end{array}$ & $41 / 1415(2.9)$ & 22/993 (2.2) & 19/422 (4.5) & 0.019 \\
\hline Stable & 486/1415 (34.3) & 449/993 (45.2) & $37 / 422(8.8)$ & $<0.001$ \\
\hline Growth $\neq$ & 130/1,415 (9.2) & $117 / 993(11.8)$ & 13/422 (3.1) & $<0.001$ \\
\hline $\begin{array}{l}\text { Part-solid nodules that } \\
\text { underwent invasive biopsy, } \\
\mathrm{n}(\%)\end{array}$ & $176(10.9)$ & $162(14.1)$ & $14(3.1)$ & $<0.001$ \\
\hline $\begin{array}{l}\text { Diagnosed as lung cancer, } \\
\text { n (\%) }\end{array}$ & $151(9.4)$ & $143(12.4)$ & $8(1.8)$ & $<0.001$ \\
\hline $\begin{array}{l}\text { Diagnosed as benign (false- } \\
\text { positive), } \mathrm{n}(\%)\end{array}$ & $24(1.5)$ & $18(1.6)$ & $6(1.3)$ & 0.714 \\
\hline
\end{tabular}

*The $p$ value is based on the comparison between baseline nodules and new nodules.

tNodules that disappeared or exhibited a decrease of $\geq 2 \mathrm{~mm}$ in total size or in the solid portion.

₹Nodules that exhibited an increase of $\geq 2 \mathrm{~mm}$ in the total size or solid portion, or a new solid portion emerged. LDCT, low-dose chest CT; RADS, reporting and data system.

Of all participants with subsolid nodules, one with stage IIIC poorly differentiated carcinoma and three with stage IV adenocarcinoma were lost to follow-up due to patient refusal and later presented with advanced diseases. During the study period, eight patients experienced recurrence after surgical treatment. Two lung cancer-related deaths were reported (mean (SD) follow-up period from diagnosis of lung cancer to death: 28.7 (9.3) months).
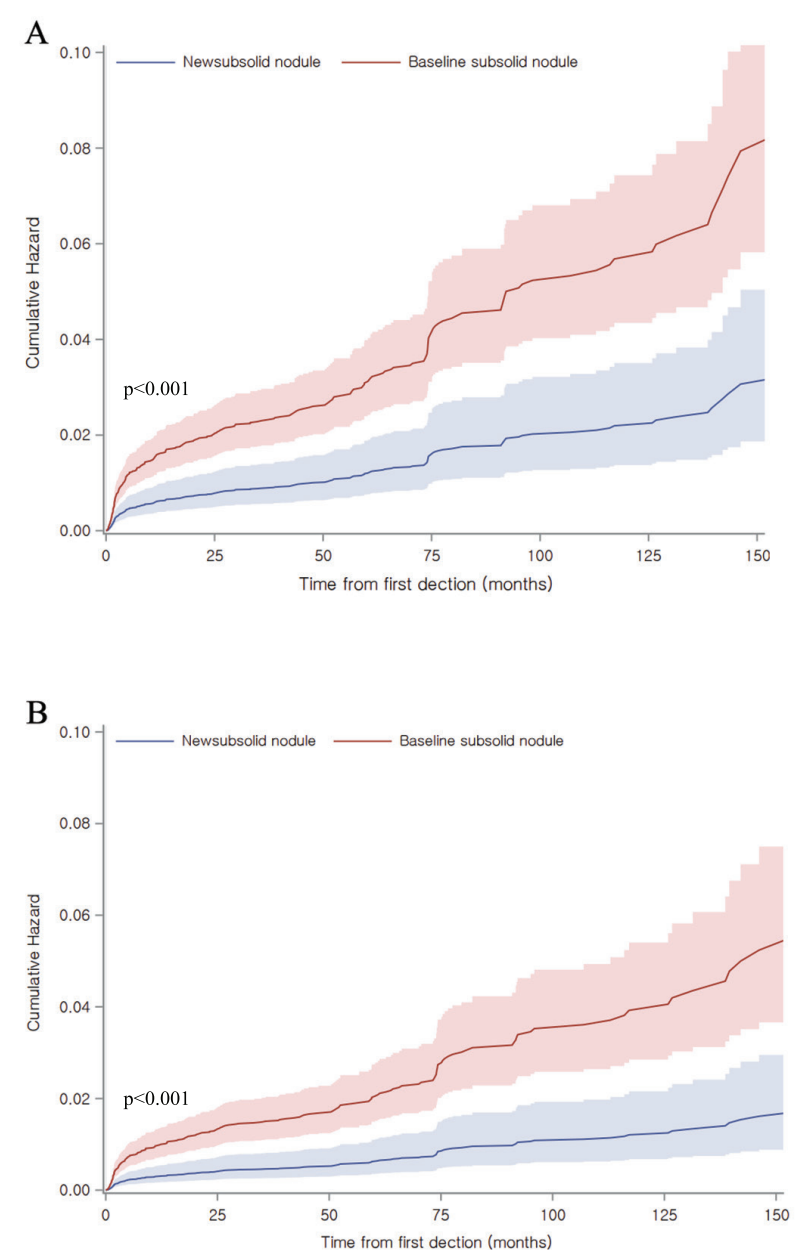

Figure 2 Cumulative hazards of (A) invasive biopsy and (B) lung cancer diagnosis for the baseline and new subsolid nodules (total $n=6725$ ).

\section{Analysis of risk factors associated with the outcomes of screen-detected subsolid nodules}

Table 6 presents the results of univariable and multivariable analyses of potential risk factors associated with the clinical outcomes of screen-detected subsolid nodules. The multivariable analysis revealed that older age at detection (OR 1.03, 95\% CI 1.02 to 1.05), larger initial diameter (OR 1.16, 95\% CI 1.12 to 1.20 ) and initial presentation as a part-solid nodule (OR 4.45, 95\% CI 3.06 to 6.46 ) were significantly associated with a higher probability of lung cancer diagnosis, and new detection at follow-up screening was significantly associated with a lower probability (OR 0.26 95\% CI 0.14 to 0.49 ) of lung cancer diagnosis. New detection at follow-up screening was significantly associated with a lower probability of overall growth of a subsolid nodule (OR $0.39,95 \%$ CI 0.26 to 0.59 ) and higher probability of resolution (OR 6.30, 95\% CI 5.09 to 7.81 ).

\section{DISCUSSION}

In this study, from a large hospital-based cohort of lung cancer screening in South Korea, we determined the occurrence of subsolid nodules, including pure GGNs and part-solid nodules at baseline and follow-up LDCT screening according to smoking status. Furthermore, we assessed the lung cancer probability and 


\begin{tabular}{|c|c|c|c|c|}
\hline & Total $(n=293)$ & $\begin{array}{l}\text { Baseline subsolid } \\
\text { nodule }(n=266)\end{array}$ & $\begin{array}{l}\text { New subsolid } \\
\text { nodule }(n=27)\end{array}$ & P value* \\
\hline Time of biopsy, n (\%) & & & & 0.793 \\
\hline At first detection & $49(16.7)$ & $44(16.5)$ & $5(18.5)$ & \\
\hline After follow-up & $244(83.3)$ & $222(83.5)$ & $22(81.5)$ & \\
\hline $\begin{array}{l}\text { Time from first detection to } \\
\text { biopsy (months), mean } \pm S D\end{array}$ & $29.8 \pm 39.4$ & $30.1 \pm 39.7$ & $26.7 \pm 37.1$ & 0.651 \\
\hline $\begin{array}{l}\text { Type of initial biopsy for } \\
\text { diagnosis, } n(\%)\end{array}$ & & & & 0.267 \\
\hline $\begin{array}{l}\text { Video-assisted thoracic } \\
\text { surgery }\end{array}$ & $258(88.1)$ & $236(88.7)$ & $22(81.5)$ & \\
\hline $\begin{array}{l}\text { Percutaneous needle } \\
\text { biopsy }\end{array}$ & $30(10.2)$ & $25(9.4)$ & $5(18.5)$ & \\
\hline $\begin{array}{l}\text { Bronchoscopy-guided } \\
\text { biopsy }\end{array}$ & $5(1.7)$ & $5(1.9)$ & $0(0)$ & \\
\hline $\begin{array}{l}\text { Range of surgical resection, } \\
\mathrm{n} / \mathrm{N}(\%) \dagger\end{array}$ & & & & 0.249 \\
\hline Lobectomy & $146 / 276(52.9)$ & $136 / 252(54.0)$ & $10 / 24(41.7)$ & \\
\hline $\begin{array}{l}\text { Segmentectomy or wedge } \\
\text { resection }\end{array}$ & $130 / 276(47.1)$ & $116 / 252(46.0)$ & $14 / 24(58.3)$ & \\
\hline $\begin{array}{l}\text { Required rebiopsy for } \\
\text { insufficient diagnosis, } n(\%)\end{array}$ & $2(0.7)$ & $2(0.8)$ & $0(0)$ & 1.000 \\
\hline $\begin{array}{l}\text { Complications related to } \\
\text { invasive biopsy, } \mathrm{n}(\%)\end{array}$ & & & & - \\
\hline $\begin{array}{l}\text { Pneumothorax requiring } \\
\text { pleurodesis }\end{array}$ & $23(7.8)$ & $22(8.3)$ & $1(3.7)$ & \\
\hline Postoperative pneumonia & $3(1.0)$ & $3(1.1)$ & $0(0)$ & \\
\hline $\begin{array}{l}\text { Bleeding requiring } \\
\text { additional intervention }\end{array}$ & $2(0.7)$ & $2(0.8)$ & $0(0)$ & \\
\hline $\begin{array}{l}\text { Pulmonary } \\
\text { thromboembolism }\end{array}$ & $1(0.3)$ & $1(0.4)$ & $0(0)$ & \\
\hline Vocal cord palsy & 10.3) & $1(0.4)$ & $0(0)$ & \\
\hline Chylothorax & $7(2.4)$ & $7(2.6)$ & $0(0)$ & \\
\hline Bronchial stenosis & $1(0.3)$ & $1(0.4)$ & $0(0)$ & \\
\hline Persistent pleural effusion & $5(1.7)$ & $5(1.9)$ & $0(0)$ & \\
\hline $\begin{array}{l}\text { Acute coronary syndrome } \\
\text { or stroke }\end{array}$ & $1(0.3)$ & $0(0)$ & $1(3.7)$ & \\
\hline $\begin{array}{l}\text { Diagnosed as lung cancer, } \\
\mathrm{n}(\%)\end{array}$ & $227(77.5)$ & $210(78.9)$ & $17(63.0)$ & 0.058 \\
\hline $\begin{array}{l}\text { Diagnosed as benign (false- } \\
\text { positive), } \mathrm{n}(\%)\end{array}$ & $65(22.2)$ & $55(20.7)$ & $10(37.0)$ & 0.051 \\
\hline $\begin{array}{l}\text { Pathological diagnosis of } \\
\text { benign nodule, } n / \mathrm{N}(\%)\end{array}$ & & & & 0.009 \\
\hline AAH & $34 / 65(52.3)$ & $32 / 55(58.2)$ & $2 / 10(20.0)$ & \\
\hline Focal fibrosis & 9/65 (13.8) & 9/55 (16.4) & $0 / 10(0)$ & \\
\hline Inflammatory nodule $\ddagger$ & $17 / 65(26.2)$ & $11 / 55(20.0)$ & $6 / 10(60.0)$ & \\
\hline Other benign condition§ & $5 / 65(7.7)$ & $3 / 55(5.5)$ & $2 / 10(20.0)$ & \\
\hline
\end{tabular}

*The $p$ value is based on the comparison between baseline and new nodules.
†All nodules resected for diagnosis or treatment underwent video-assisted thoracic surgery with the exception tAll nodules resected for diagnosis or treatment underwent video-assisted thoracic surgery with the exception
of one case that converted to open thoracotomy during video-assisted thoracic surgery due to uncontrolled bleeding FIncluding chronic inflammation and infectious nodules.

§Including nodules related with cryptogenic organising pneumonia, vasculitis, lgG4 disease and placenta transmogrification.

$\mathrm{AAH}$, atypical adenomatous hyperplasia.

clinical outcomes, and provided information on the pathology and cancer stage of baseline and new screen-detected subsolid nodules. Inclusion of asymptomatic participants who voluntarily underwent LDCT screening enabled the evaluation of a large number of never-smokers and those of relatively younger age, and reflects the actual state of LDCT screening in Asia, where LDCT screening is widely applied to these populations. ${ }^{32} \mathrm{We}$ found that the incidence of screen-detected subsolid nodules was significantly higher in never-smokers $(10.7 \%)$ than in eversmokers $(7.7 \%)$, and that the characteristics and outcomes of
Table 5 Characteristics of screen-detected subsolid nodules diagnosed as lung cancer

\begin{tabular}{|c|c|c|c|c|}
\hline & Total $(n=227)$ & $\begin{array}{l}\text { Baseline subsolid } \\
\text { nodule }(n=210)\end{array}$ & $\begin{array}{l}\text { New subsolid } \\
\text { nodule }(n=17)\end{array}$ & P value* \\
\hline $\begin{array}{l}\text { Nodule type at first detection, } \\
\mathrm{n}(\%)\end{array}$ & & & & 0.077 \\
\hline Pure GGN & $76(33.5)$ & $67(31.9)$ & $9(52.9)$ & \\
\hline Part solid & $151(66.5)$ & $143(68.1)$ & $8(47.1)$ & \\
\hline $\begin{array}{l}\text { Diameter at first detection }(\mathrm{mm}) \text {, } \\
\text { mean } \pm S D\end{array}$ & $12.8 \pm 7.0$ & $12.3 \pm 6.8$ & $11.8 \pm 9.2$ & 0.665 \\
\hline Histological classification, n (\%) & & & & 0.680 \\
\hline AIS & $31(13.7)$ & $30(14.3)$ & $1(5.9)$ & \\
\hline MIA & $59(26.0)$ & $53(25.2)$ & $6(35.3)$ & \\
\hline Invasive adenocarcinoma & $136(59.9)$ & $126(60.0)$ & $10(58.8)$ & \\
\hline Poorly differentiated NSCLC & $1(0.4)$ & $1(0.5)$ & $0(0)$ & \\
\hline Stage at diagnosis, n (\%)† & & & & - \\
\hline $0 \neq$ & $31(13.7)$ & $30(14.3)$ & $1(5.9)$ & \\
\hline IA & $175(77.1)$ & $160(76.2)$ & $15(88.2)$ & \\
\hline IB & $12(5.3)$ & $11(5.2)$ & $1(5.9)$ & \\
\hline$\| \mathrm{A}$ & $2(0.9)$ & $2(1.0)$ & $0(0)$ & \\
\hline IIB & $1(0.4)$ & $1(0.5)$ & $0(0)$ & \\
\hline IIIA & $1(0.4)$ & $1(0.5)$ & $0(0)$ & \\
\hline IIIB & $0(0)$ & $0(0)$ & $0(0)$ & \\
\hline IIIC & $1(0.4)$ & $1(0.5)$ & $0(0)$ & \\
\hline IV & $4(1.8)$ & $4(1.9)$ & $0(0)$ & \\
\hline Time of biopsy, $n$ (\%) & & & & 0.744 \\
\hline At first detection & $39(17.2)$ & $37(17.6)$ & $2(11.8)$ & \\
\hline After follow-up & $188(82.8)$ & $173(82.4)$ & $15(88.2)$ & \\
\hline $\begin{array}{l}\text { Time from first detection to } \\
\text { biopsy (months), mean } \pm \text { SD }\end{array}$ & $30.8 \pm 39.9$ & $30.4 \pm 39.8$ & $36.0 \pm 42.9$ & 0.608 \\
\hline
\end{tabular}

subsolid nodules differed between never-smokers and eversmokers. New subsolid nodules had a higher resolution rate (78.9\% vs $30.0 \%)$, and lower rates of biopsy ( $1.8 \%$ vs $5.1 \%)$ and lung cancer diagnosis (1.1\% vs $4.0 \%$ ) than baseline subsolid nodules. After adjustments for other potential factors, new detection at follow-up screening remained a low risk factor for lung cancer diagnosis (OR $0.26,95 \% \mathrm{CI} 0.14$ to 0.49 ) and growth (OR $0.39,95 \% \mathrm{CI} 0.26$ to 0.59 ) and a high-risk factor for resolution (OR 6.30, 95\% CI 5.09 to 7.81) compared with baseline detection. Our results indicate that a substantial subsolid nodule detection rate is expected in similar lung cancer screening settings in Asia, particularly among never-smokers. New subsolid nodules were associated with a lower probability of lung cancer and a higher probability of spontaneous resolution than baseline subsolid nodules. Unlike new solid nodules, more aggressive follow-up for new subsolid nodules is not warranted.

To date, several large lung cancer screening studies have reported the prevalence of subsolid nodules. However, to our knowledge, the International Early Lung Cancer Action Programme (I-ELCAP), and the NELSON trial are the only two large studies to publish separate data on the incidence of baseline and new subsolid nodules. ${ }^{10} 112125$ According to the I-ELCAP data, $4.2 \%$ and $5.0 \%$ of the participants had at least one baseline-detected pure GGN and part-solid nodule, respectively. In addition, new pure GGNs and part-solid nodules were detected in $0.7 \%$ and $0.8 \%$ of annual repeat screenings, respectively. The NELSON trial reported that $3.3 \%$ of participants had 


\begin{tabular}{|c|c|c|c|c|c|}
\hline \multirow[b]{2}{*}{ Clinical outcome } & \multirow[b]{2}{*}{ Variable* } & \multicolumn{2}{|l|}{ Univariable analysis } & \multicolumn{2}{|c|}{ Multivariable analysis } \\
\hline & & OR $(95 \% \mathrm{Cl})$ & $P$ value & OR $(95 \% \mathrm{Cl})$ & $P$ value \\
\hline \multirow[t]{7}{*}{ Lung cancer diagnosis } & Detected at follow-up screening & 0.30 (0.17 to 0.52 ) & $<0.001$ & $0.26(0.14$ to 0.49$)$ & $<0.001$ \\
\hline & Sex (male) & 1.00 (0.74 to 1.35 ) & 0.991 & 0.90 (0.58 to 1.40$)$ & 0.643 \\
\hline & Age at detection & 1.05 (1.04 to 1.06$)$ & $<0.001$ & $1.03(1.02$ to 1.05$)$ & $<0.001$ \\
\hline & Smoking status (ever-smoker) & 1.09 (0.81 to 1.46$)$ & 0.582 & 1.15 (0.75 to 1.77$)$ & 0.522 \\
\hline & Initial diameter & 1.23 (1.19 to 1.27$)$ & $<0.001$ & $1.16(1.12$ to 1.20$)$ & $<0.001$ \\
\hline & Multiplicity & 0.72 (0.52 to 0.99 ) & 0.040 & 1.24 (0.87 to 1.76$)$ & 0.236 \\
\hline & Part-solid nodule (vs pure GGN) & $9.28(6.60$ to 13.04$)$ & $<0.001$ & 4.45 (3.06 to 6.46$)$ & $<0.001$ \\
\hline \multirow[t]{7}{*}{ Growtht } & Detected at follow-up screening & 0.35 (0.24 to 0.52$)$ & $<0.001$ & $0.39(0.26$ to 0.59$)$ & $<0.001$ \\
\hline & Sex (male) & 0.91 (0.70 to 1.19 ) & 0.503 & 0.96 (0.66 to 1.40$)$ & 0.835 \\
\hline & Age at detection & 1.04 (1.03 to 1.05$)$ & $<0.001$ & 1.03 (1.02 to 1.04$)$ & $<0.001$ \\
\hline & Smoking status (ever-smoker) & 0.95 (0.73 to 1.23$)$ & 0.682 & 0.95 (0.73 to 1.23$)$ & 0.498 \\
\hline & Initial diameter & 1.12 (1.09 to 1.15$)$ & $<0.001$ & 1.08 (1.05 to 1.11$)$ & $<0.001$ \\
\hline & Multiplicity & 0.53 (0.40 to 0.71$)$ & $<0.001$ & 0.66 (0.49 to 0.88$)$ & 0.005 \\
\hline & Part-solid nodule (vs pure GGN) & 2.47 (1.92 to 3.19$)$ & $<0.001$ & 1.76 (1.31 to 2.36$)$ & $<0.001$ \\
\hline \multirow[t]{7}{*}{ Resolution $\neq$} & Detected at follow-up screening & 5.40 (3.89 to 7.50$)$ & $<0.001$ & 6.30 (5.09 to 7.81$)$ & $<0.001$ \\
\hline & Sex (male) & 2.74 (2.33 to 3.22 ) & $<0.001$ & 1.89 (1.52 to 2.35$)$ & $<0.001$ \\
\hline & Age at detection & 0.97 (0.96 to 0.98 ) & $<0.001$ & 0.98 (0.97 to 0.98$)$ & $<0.001$ \\
\hline & Smoking status (ever-smoker) & 2.32 (2.01 to 2.69 ) & $<0.001$ & 1.34 (1.10 to 1.64$)$ & 0.004 \\
\hline & Initial diameter & 1.01 (0.99 to 1.03$)$ & 0.248 & 1.03 (1.01 to 1.05$)$ & 0.003 \\
\hline & Multiplicity & 2.07 (1.68 to 2.54$)$ & $<0.001$ & 2.57 (2.16 to 3.05$)$ & $<0.001$ \\
\hline & Part-solid nodule (vs pure GGN) & 1.17 (0.99 to 1.37 ) & 0.059 & 1.55 (1.33 to 1.79$)$ & $<0.001$ \\
\hline
\end{tabular}

*Age and initial diameter (in $\mathrm{mm}$ ) were included as continuous variables, and sex, smoking status, detection at follow-up screening, multiplicity and nodule type were included as categorical variables.

tExhibiting an increase of $\geq 2 \mathrm{~mm}$ in the total size or solid portion, or emerging new solid portion. Regression analyses are based on nodules that received follow-up ( $n=4918$ ).

‡Disappeared or exhibited a decrease of $\geq 2 \mathrm{~mm}$ in the total size or in the solid portion. Regression analyses are based on nodules that received follow-up ( $n=4918)$.

GGN, ground glass opacity nodule.

subsolid nodules detected during the trial, and $0.7 \%$ of participants had new subsolid nodules detected during follow-up. The NLST, which is largest randomised lung cancer screening trial to date, indicated that at least one subsolid nodule was detected in 9.4\% of participants during baseline and follow-up screening, but no distinction was made between baseline and new subsolid nodules. ${ }^{33}$ However, we must consider that previous large screening studies enrolled mainly Caucasian smokers. Since subsolid nodules are known to be more prevalent in women and never-smokers of Asian origin, different optimal management strategies might be needed for lung cancer screening in different clinical settings. ${ }^{19}{ }^{34}$ In our study, which evaluated the largest number of screen-detected subsolid nodules and represented lung cancers to date, 9.1\% participants had at least one subsolid nodule detected during the follow-up period, with $1.9 \%$ participants newly detected at follow-up screening. The detection rate was $10.7 \%$ among never-smokers, which was higher than the rate among ever-smokers and the rate reported in previous studies. ${ }^{10112133}$ Ever-smokers had a higher rate of detection of new, multiple, part-solid nodules that resolved spontaneously than did never-smokers. Results from our study indicate that more cautious and long-term follow-up is needed for screen-detected subsolid nodules in Asians, particularly in never-smokers.

According to current guidelines, the management of subsolid nodules is mainly based on nodule type, size and growth, and is not additionally weighted by smoking status or age. Limited information is available on the incidence and lung cancer probability of baseline and new subsolid nodules. ${ }^{35}$ Moreover, it remains unknown whether current screening guidelines are applicable in Asian populations, since the incidence and characteristics of subsolid nodules seem to differ according to race and regions. ${ }^{21}$ Currently, in most guidelines, no differentiation is made between the management of baseline and new subsolid nodules. ${ }^{16} 1836$ In lung-RADS, the management of subsolid nodules detected at baseline or follow-up is distinguished, recommending more aggressive follow-up or diagnostic evaluation for new subsolid nodules. ${ }^{24}$ In the I-ELCAP study, nearly $70 \%$ of new subsolid nodules resolved or decreased in size at follow-up, and 3.8\% of new subsolid nodules (compared with $2.9 \%$ of baseline subsolid nodules) were finally diagnosed as lung cancer. ${ }^{10} 11$ The NELSON trial reported a markedly lower incidence of screen-detected subsolid nodules and only three cases of lung cancer diagnosed from new subsolid nodules. Although similar trends were found in the high likelihood of resolution in new subsolid nodules, the probability of lung cancer in new subsolid nodules $(6 \%)$ was relatively high. ${ }^{21} 25$ In our study, $30.0 \%$ of baseline subsolid nodules and $78.9 \%$ of new subsolid nodules among those underwent additional follow-up disappeared or decreased in size. Moreover, 7.1\% of baseline subsolid nodules and $2.5 \%$ of new subsolid nodules exhibited growth. Overall, 210 (4.0\%) baseline subsolid nodules and $17(1.1 \%)$ new subsolid nodules were diagnosed as lung cancer. Compared with the I-ELCAP, the probability of baseline subsolid nodules being cancerous was higher, whereas the probability of new subsolid nodules being cancerous was lower. In contrast to the I-ELCAP and NELSON trial, our data showed a lower cancer probability of new subsolid nodules compared with baseline subsolid nodules. ${ }^{10} 112225$ Our findings indicate that future guidelines can allow less aggressive follow-up for newly detected subsolid nodules, particularly in screening programmes for Asian population. 
In our study, all subsolid nodules, except one, diagnosed as lung cancer were adenocarcinomas. Over $95 \%$ of lung cancers were diagnosed as stage 0 or stage I, and $39.7 \%$ were diagnosed as preinvasive adenocarcinoma (adenocarcinoma in situ or minimally invasive adenocarcinoma). There was no significant difference in the stage, duration from first detection to diagnosis, and distribution of (pre)invasive adenocarcinomas between baseline and new subsolid nodules diagnosed as lung cancer. This indicates that, unlike new solid nodules that are considered to be rapid growing, ${ }^{23} 37$ new subsolid nodules indicative of lung cancer have a less aggressive course and follow-up without shortening the screening intervals on these nodules would be reasonable. ${ }^{1038}$ Nevertheless, the notable recurrence rate and number of patients lost to follow-up who later presented with advanced disease in our study underline the need for meticulous screening and awareness of possible lung cancer in patients with detected subsolid nodules.

Among subsolid nodules that were biopsied but turned out to be benign, $74.6 \%$ of subsolid nodules detected at baseline were AAH or focal fibrosis, whereas the majority $(60.0 \%)$ of new subsolid nodules were inflammatory nodules. Along with a high probability of resolution, this indicates the mainly inflammatory nature of newly detected subsolid nodules. ${ }^{39}{ }^{40}$ This is also supported by the fact that new subsolid nodules were prevalent in ever-smokers, since smoking is well known to cause lung inflammation. Thus, for new subsolid nodules, the probability of transient inflammation or infectious conditions should be always considered. Based on our results, follow-up CT rather than direct pathological diagnosis may be a relevant strategy, even for category $4 \mathrm{~A}$ or $4 \mathrm{~B}$ new subsolid nodules classified according to the lung-RADS classification.

This study has several limitations. First, this was a retrospective study from a single centre, and the strategy for LDCT screening and follow-up was not strictly controlled. Therefore, follow-up intervals or durations for detected subsolid nodules were not constant. Moreover, it was impossible to fully assess potential factors that could have influenced the decision to perform biopsy and diagnosis, which leaves the potential for selection bias. However, the lack of prospective controlled screening studies and difficulty in conducting such studies including populations with a high prevalence of subsolid nodules, such as female never-smokers must be considered. Subsolid nodules generally require lengthy follow-up, and can change after a long time of stabilisation, making it difficult to control follow-up strategies. ${ }^{41}$ Second, due to the indolent course and long time needed for follow-up, not all subsolid nodules suspected of malignancy were biopsied. Some suspicious but stable subsolid nodules are regularly followed up. Therefore, the number and proportion of diagnosed lung cancer among screen-detected subsolid nodules may have been underestimated. Third, we could not evaluate racial differences in the incidence and outcomes of screendetected subsolid nodules because all participants were Korean, far-east Asian. For ever-smokers, information on the level of smoking and duration of smoking cessation was not available for a number of participants, making further subgroup analyses impossible. Fourth, no adjustment for multiple comparisons were made for the analyses in our study, thus providing weak control for possible multiple testing problems.

The main strength of our study is the large sample size of a hospital cohort. Our study provides unique and relevant data acquired from the real-world setting of an asymptomatic Asian population that underwent LDCT screening at a tertiary medical centre. The results not only offer insight into the cancer probability or outcomes of screen-detected subsolid nodules, but also provides relevant histological information including falsepositive results and cancer stage.

In conclusion, LDCT screening resulted in a considerable detection rate of subsolid nodules that needed further follow-up and evaluation. For never-smokers, more cautious and longterm follow-up is needed. New subsolid nodules had a lower probability of lung cancer and a higher probability for spontaneous resolution than baseline subsolid nodules, indicating their inflammatory nature. Therefore, less aggressive follow-up may be allowed for new subsolid nodules, particularly in screening programmes for Asian populations.

Funding This study was supported by the Seoul National University Bundang Hospital (grant number 06-2019-356).

Competing interests None declared.

Patient consent for publication Not required.

Ethics approval The study design was approved by the Institutional Review Board of Seoul National University Bundang Hospital (IRB no: B-1911-576-004).

Provenance and peer review Not commissioned; externally peer reviewed. Data availability statement Data are available on reasonable request.

Open access This is an open access article distributed in accordance with the Creative Commons Attribution Non Commercial (CC BY-NC 4.0) license, which permits others to distribute, remix, adapt, build upon this work non-commercially, and license their derivative works on different terms, provided the original work is properly cited, appropriate credit is given, any changes made indicated, and the use is non-commercial. See: http://creativecommons.org/licenses/by-nc/4.0/.

\section{ORCID iDs}

Yeon Wook Kim http://orcid.org/0000-0001-8333-4812

Choon-Taek Lee http://orcid.org/0000-0001-8030-3332

\section{REFERENCES}

1 National Lung Screening Trial Research Team, Aberle DR, Adams AM, et al. Reduced lung-cancer mortality with low-dose computed tomographic screening. N Engl J Med 2011:365:395-409.

2 de Koning $\mathrm{HJ}$, van der Aalst CM, de Jong PA, et al. Reduced lung-cancer mortality with volume CT screening in a randomized trial. N Engl J Med 2020;382:503-13.

3 Moyer VA US. Preventive services Task force. screening for lung cancer: U. S. Preventive Services Task Force recommendation statement. Ann Intern Med 2014;160:330-8.

4 Wang Y, Midthun DE, Wampfler JA, et al. Trends in the proportion of patients with lung cancer meeting screening criteria. JAMA 2015;313:853-5.

5 Luo Y-H, Luo L, Wampfler JA, et al. 5-Year overall survival in patients with lung cancer eligible or ineligible for screening according to US preventive services Task force criteria: a prospective, observational cohort study. Lancet Oncol 2019;20:1098-108.

6 Yano T, Miura N, Takenaka T, et al. Never-Smoking nonsmall cell lung cancer as a separate entity: clinicopathologic features and survival. Cancer 2008:113:1012-8.

7 Thun MJ, Hannan LM, Adams-Campbell LL, et al. Lung cancer occurrence in never-smokers: an analysis of 13 cohorts and 22 cancer registry studies. PLoS Med 2008;5:e185.

8 Zhao S-J, Wu N. Early detection of lung cancer: low-dose computed tomography screening in China. Thorac Cancer 2015;6:385-9.

9 Triphuridet N, Henschke C. Landscape on CT screening for lung cancer in Asia. Lung Cancer 2019;10:107-24.

10 Yankelevitz DF, Yip R, Smith JP, et al. Ct screening for lung cancer: Nonsolid nodules in baseline and annual repeat rounds. Radiology 2015;277:555-64.

11 Henschke Cl, Yip R, Smith JP, et al. Ct screening for lung cancer: Part-Solid nodules in baseline and annual repeat rounds. AJR Am J Roentgenol 2016;207:1176-84.

12 Lee C-T. What do we know about ground-glass opacity nodules in the lung? Trans/ Lung Cancer Res 2015;4:656-9.

13 McWilliams A, Tammemagi MC, Mayo JR, et al. Probability of cancer in pulmonary nodules detected on first screening CT. N Engl J Med 2013;369:910-9.

14 Kobayashi Y, Fukui T, Ito $S$, et al. How long should small lung lesions of ground-glass opacity be followed? J Thorac Oncol 2013;8:309-14.

15 Cho J, Kim ES, Kim SJ, et al. Long-Term follow-up of small pulmonary Ground-Glass nodules stable for 3 years: implications of the proper follow-up period and risk factors for subsequent growth. J Thorac Oncol 2016:11:1453-9.

16 MacMahon H, Naidich DP, Goo JM, et al. Guidelines for management of incidental pulmonary nodules detected on CT images: from the Fleischner Society 2017. Radiology 2017;284:228-43.

17 National Comprehensive Cancer Network. NCCN Guildelines. version 1.2020, 2019https:. Available: www.nccn.org/professionals/physician_gls/pdf/lung_screening/ pdf 
18 Baldwin DR, Callister MEJ, Guideline Development Group. The British thoracic Society guidelines on the investigation and management of pulmonary nodules. Thorax 2015;70:794-8.

19 Kobayashi Y, Ambrogio C, Mitsudomi T. Ground-glass nodules of the lung in never-smokers and smokers: clinical and genetic insights. Trans/ Lung Cancer Res 2018;7:487-97.

20 Silva M, Mario S, Sverzellati N, Manna C, et al. Long-Term surveillance of ground-glass nodules: evidence from the mild trial. J Thorac Oncol 2012;7:1541-6.

21 Scholten ET, de Jong PA, de Hoop B, et al. Towards a close computed tomography monitoring approach for screen detected subsolid pulmonary nodules? Eur Respir J 2015;45:765-73.

22 Walter JE, Heuvelmans MA, de Jong PA, et al. Occurrence and lung cancer probability of new solid nodules at incidence screening with low-dose CT: analysis of data from the randomised, controlled Nelson trial. Lancet Oncol 2016;17:907-16.

23 Henschke $\mathrm{Cl}$, Yankelevitz DF, Yip R, et al. Lung cancers diagnosed at annual CT screening: volume doubling times. Radiology 2012;263:578-83.

24 American College of Radiology. Lung cancer screening reporting and data system (Lung-RADS), 2019. Available: http://www.acr.org

25 Walter JE, Heuvelmans MA, Yousaf-Khan U, et al. New Subsolid pulmonary nodules in lung cancer screening: the Nelson trial. J Thorac Oncol 2018;13:1410-4.

26 Pallis AG, Syrigos KN. Lung cancer in never smokers: disease characteristics and risk factors. Crit Rev Oncol Hematol 2013;88:494-503.

27 Hiramatsu M, Inagaki T, Inagaki T, et al. Pulmonary ground-glass opacity (GGO) lesions-large size and a history of lung cancer are risk factors for growth. J Thorac Oncol 2008;3:1245-50.

28 Travis WD, Asamura H, Bankier AA, et al. The IASLC lung cancer staging project: proposals for coding $T$ categories for Subsolid nodules and assessment of tumor size in Part-Solid tumors in the forthcoming eighth edition of the TNM classification of lung cancer. J Thorac Oncol 2016;11:1204-23.

29 Goldstraw P, Chansky K, Crowley J, et al. The IASLC lung cancer staging project: proposals for revision of the TNM stage groupings in the forthcoming (eighth) edition of the TNM classification for lung cancer. J Thorac Oncol 2016;11:39-51.
30 Travis WD, Brambilla E, Nicholson AG, et al. The 2015 World Health organization classification of lung tumors: impact of genetic, clinical and radiologic advances since the 2004 classification. J Thorac Oncol 2015;10:1243-60.

31 Travis WD, Brambilla E, Burke AP, et al. Who classification of tumours of the lung, pleura, thymus and heart. Lyon: International Agency for Research on Cancer, 2015.

32 Kondo R, Yoshida K, Kawakami S, et al. Efficacy of CT screening for lung cancer in never-smokers: analysis of Japanese cases detected using a low-dose CT screen. Lung Cancer 2011;74:426-32.

33 Yip R, Yankelevitz DF, Hu M, et al. Lung cancer deaths in the National lung screening trial attributed to Nonsolid nodules. Radiology 2016;281:589-96.

34 Kang H-R, Cho JY, Lee SH, et al. Role of low-dose computerized tomography in lung cancer screening among never-smokers. J Thorac Oncol 2019;14:436-44.

35 Heuvelmans MA, Walter JE, Oudkerk M. Management of baseline and new sub-solid nodules in CT lung cancer screening. Expert Rev Respir Med 2018;12:1-3.

36 Gould MK, Donington J, Lynch WR, et al. Evaluation of individuals with pulmonary nodules: when is it lung cancer? diagnosis and management of lung cancer, 3rd ED: American College of chest physicians evidence-based clinical practice guidelines. Chest 2013;143:e93S-120.

37 Carter D, Vazquez M, Flieder DB, et al. Comparison of pathologic findings of baseline and annual repeat cancers diagnosed on CT screening. Lung Cancer 2007;56:193-9.

38 Hammer MM, Palazzo LL, Eckel AL, et al. A decision analysis of followup and treatment algorithms for Nonsolid pulmonary nodules. Radiology 2019;290:506-13.

39 Oh J-Y, Kwon S-Y, Yoon H-I, et al. Clinical significance of a solitary ground-glass opacity (GGO) lesion of the lung detected by chest CT. Lung Cancer 2007;55:67-73.

40 Lee SM, Park CM, Goo JM, et al. Transient part-solid nodules detected at screening thin-section CT for lung cancer: comparison with persistent part-solid nodules. Radiology 2010;255:242-51.

41 Lee HW, Jin K-N, Lee J-K, et al. Long-Term follow-up of Ground-Glass nodules after 5 years of stability. J Thorac Oncol 2019;14:1370-7. 